\title{
Association Analysis in Children Born from Normal and Complicated Pregnancies-Cardiovascular Disease Associated microRNAs and the Incidence of Prehypertension/Hypertension, Overweight/Obesity, Valve Problems and Heart Defects
}

\author{
Ilona Hromadnikova ${ }^{1, * \mathbb{D}}$, Katerina Kotlabova ${ }^{1}$, Ladislav Krofta ${ }^{2}$ and Jan Sirc ${ }^{2}$ (D) \\ 1 Department of Molecular Biology and Cell Pathology, Third Faculty of Medicine, Charles University, \\ 10000 Prague, Czech Republic; katerina.kotlabova@lf3.cuni.cz \\ 2 Institute for the Care of the Mother and Child, Third Faculty of Medicine, Charles University, \\ 14700 Prague, Czech Republic; ladislav.krofta@upmd.eu (L.K.); jan.sirc@upmd.eu (J.S.) \\ * Correspondence: ilona.hromadnikova@lf3.cuni.cz; Tel.: +420-296511336
}

Received: 19 October 2020; Accepted: 9 November 2020; Published: 9 November 2020

check for updates

\begin{abstract}
The goal was to assess how a history of any kind of pregnancy-related complication altered expression profile of microRNAs played a role in the pathogenesis of diabetes, cardiovascular and cerebrovascular diseases in the peripheral blood leukocytes of children at the age of 3-11 years. The prior exposure to gestational hypertension, preeclampsia, fetal growth restriction, gestational diabetes mellitus, preterm prelabor rupture of membranes or spontaneous preterm birth causes that a significant proportion of children ( $57.42 \%$ to $90.0 \%$ specifically) had a substantially altered microRNA expression profile, which might be the origin of a lifelong cardiovascular risk. A total of 23 out of 29 tested microRNAs were upregulated in children born from such complicated gestation. The occurrence of overweight, obesity, valve problems and heart defects even intensified upregulation of microRNAs already present in children exposed to such pregnancy complications. The occurrence of overweight/obesity (miR-92a-3p, and miR-210-3p) and valve problems or heart defects (miR-342-3p) induced microRNA upregulation in children affected with pregnancy complications. Overall, $42.86 \%$ overweight/obese children and $27.36 \%$ children with valve problems or heart defects had even higher microRNA levels than children with normal clinical findings after complicated pregnancies. In addition, the microRNA expression profile was also able to differentiate between children descending from normal gestation in relation to the occurrence of overweight and obesity. Screening on the base of the combination of 19 microRNAs identified $70.0 \%$ overweight/obese children at $90.0 \%$ specificity. In general, children after complicated pregnancies, just as children after normal pregnancies, with abnormal findings are at a higher risk of the onset of cardiovascular complications, and their dispensarization, with the aim to implement primary prevention strategies, would be beneficial.
\end{abstract}

Keywords: body mass index; cardiovascular risk; children; echocardiography; heart defects; microRNA; pregnancy-related complications; prehypertension/hypertension; overweight/obesity; valve problems

\section{Introduction}

The increasing worldwide prevalence of pregnancy-related complications generates an increasing number of children with a lifelong cardiovascular risk [1-51].

Lifelong cardiovascular risk of children descending from pregnancy-related complications is based on the presence of overweight/obesity (increased body mass index and/or wider waist circumference) [1-11], 
higher systolic and/or diastolic blood pressures [1,2,6-8,12-22], higher nocturnal systolic and diastolic blood pressures [16], altered lipid profiles [6,21], altered metabolite pattern [23], impaired glucose tolerance [3,5-7,24], alteration in the systemic and the pulmonary circulation [25], altered cardiac geometry and function [26-29] and the acceleration of pubertal timing [30].

Some children born from complicated pregnancies have already been suffering from severe diseases, such as asthma [31,32], pulmonary hypertension [33-35], diabetes mellitus [36], cardiorenal metabolic syndrome [37], chronic kidney diseases [38,39], cardiovascular diseases [40], ophthalmic disorders [41], neurodevelopmental and neuropsychiatric disorders [42-51], most likely as a result of abnormal fetal programming.

Recently, we reported that a proportion of children affected with gestational hypertension (GH), preeclampsia (PE), fetal growth restriction (FGR) and gestational diabetes mellitus (GDM) had altered microRNA expression profiles that may contribute to the predisposition of these children to later onset of diabetes mellitus, cardiovascular and cerebrovascular diseases [52,53].

Prenatal exposure to maternal complications (GH, PE and GDM) or fetal complication (FGR) was associated in a proportion of children with deregulation of miR-1-3p, miR-17-5p, miR-20a-5p, miR-20b-5p, miR-21-5p, miR-23a-3p, miR-26a-5p, miR-29a-3p, miR-103a-3p, miR-125b-5p, miR-126-3p, miR-133a-3p, miR-146a-5p, miR-181a-5p, miR-195-5p, miR-210-3p and miR-342-3p [52,53].

In addition, a prior exposure to GDM induced postnatal deregulation of miR-16-5p, miR-92a-3p, miR-100-5p, miR-143-3p, miR-155-5p, miR-221-3p, miR-499a-5p and miR-574-3p [53].

The pivotal goal of the current study was to assess how a history of any kind of pregnancy complication (GH, PE, FGR, GDM, preterm prelabor rupture of membranes or spontaneous preterm birth) might contribute to postnatal alterations of microRNA expression profiles in whole peripheral venous blood (leukocytes).

In addition, the subject of our interest was extended to explore the impact of the actual occurrence of individual abnormal findings (overweight, obesity, prehypertension, hypertension, valve problems and heart defects) on already present abnormal microRNA expression profiles in children born from complicated gestation.

An additional goal of the current study was to determine to what extent individual abnormal findings (overweight, obesity, prehypertension, hypertension, valve problems and heart defects) might influence microRNA expression profiles in children born from normal gestation.

Any data on the association between microRNA expression profiles (miR-1-3p, miR-16-5p, miR-17-5p, miR-20a-5p, miR-20b-5p, miR-21-5p, miR-23a-3p, miR-24-3p, miR-26a-5p, miR-29a-3p, miR-92a-3p, miR-100-5p, miR-103a-3p, miR-125b-5p, miR-126-3p, miR-130b-3p, miR-133a-3p, miR-143-3p, miR-145-5p, miR-146a-5p, miR-155-5p, miR-181a-5p, miR-195-5p, miR-199a-5p, miR-210-3p, miR-221-3p, miR-342-3p, miR-499a-5p and miR-574-3p) in peripheral white blood cells, and the occurrence of overweight/obesity, prehypertension/hypertension, valve problems or heart defects in children aged 3-11 years born from normal and complicated gestation are currently not available.

The idea of the determination of potential diabetic/cardiovascular risk in children prenatally or perinatally affected by any kind of pregnancy-related complication was based on the fact that appropriate microRNAs are involved in the inducement and progress of diabetes mellitus, cardiovascular and cerebrovascular diseases (Table S1). We selected 29 microRNAs, which had usually been displaying aberrant expression in plasma/serum/affected tissue samples of adult and elderly patients with signs of diabetes mellitus, cardiovascular and cerebrovascular diseases.

\section{Results}

\subsection{Abnormal microRNA Expression Profile in Children Born from Complicated Pregnancies}

At first, we made a comparison of microRNA expression profile in children born from normal and complicated gestation, irrespective of the type of pregnancy-related complication (gestational diabetes 
mellitus, gestational hypertension, preeclampsia, fetal growth restriction, preterm prelabor rupture of membranes and/or spontaneous preterm birth). Both the Mann-Whitney (M-W) and receivers operating characteristic (ROC) curve analyses revealed increased expression of 23 out of 29 tested microRNAs (miR-1-3p, miR-16-5p, miR-17-5p, miR-20a-5p, miR-20b-5p, miR-21-5p, miR-23a-3p, miR-26a-5p, miR-29a-3p, miR-100-5p, miR-103a-3p， miR-125b-5p， miR-126-3p， miR-130b-3p， miR-133a-3p， miR-143-3p, miR-146a-5p, miR-181a-5p, miR-195-5p, miR-199a-5p, miR-221-3p, miR-499a-5p and miR-574-3p) in children born from complicated gestation. MicroRNAs with aberrant expression profile displayed a sensitivity with a range $10.71-31.39 \%$ at a $10.0 \%$ false positive rate (FPR) (Figure S1).

Screening on the base of a combination of all above mentioned microRNAs showed that, at $10.0 \%$ FPR, $57.42 \%$ of children born from complicated gestation had significantly altered postnatal microRNA expression profile, which may indicate an increased risk of later onset of diabetes mellitus, cardiovascular and cerebrovascular diseases (area under the curve (AUC) $0.777, p<0.001$, sensitivity $61.80 \%$, specificity $88.04 \%$, cut off $>0.819967957$ ) (Figure 1 ).

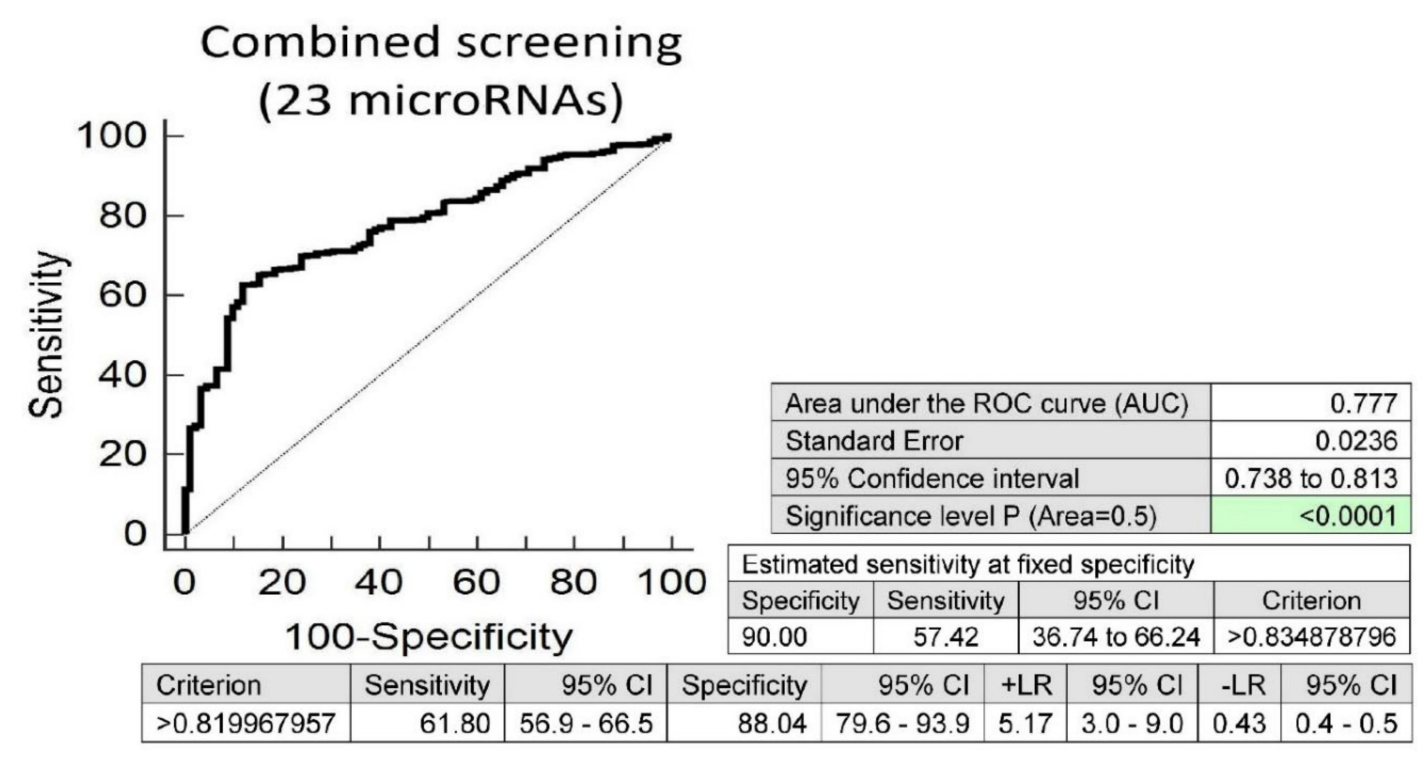

Figure 1. Aberrant microRNA expression profile in children descending from complicated pregnancies, irrespective of the type of pregnancy-related complication (gestational diabetes mellitus, gestational hypertension, preeclampsia, fetal growth restriction, preterm prelabor rupture of membranes and/or spontaneous preterm birth). Combined screening revealed that at a $10.0 \%$ false positive rate (FPR) $57.42 \%$ children prenatally exposed to any pregnancy-related complication had substantially altered microRNA expression profile (miR-1-3p, miR-16-5p, miR-17-5p, miR-20a-5p, miR-20b-5p, miR-21-5p, miR-23a-3p, miR-26a-5p, miR-29a-3p, miR-100-5p, miR-103a-3p, miR-125b-5p, miR-126-3p, miR-130b-3p, miR-133a-3p, miR-143-3p, miR-146a-5p, miR-181a-5p， miR-195-5p， miR-199a-5p， miR-221-3p, miR-499a-5p and miR-574-3p).

Subsequently, we performed comparison of microRNA expression profile between particular groups of children with respect to actual findings (normal systolic and diastolic blood pressures vs. prehypertension/hypertension; normal body mass index (BMI) vs. overweight/obesity; normal values of echocardiographic measurements vs. the occurrence of valve problems or heart defects), regardless of prenatal or perinatal exposure to pregnancy complications (gestational diabetes mellitus, gestational hypertension, preeclampsia, FGR, preterm prelabor rupture of membranes and/or spontaneous preterm birth). 
2.2. No Association between the Presence of Prehypertension/Hypertension and Expression of Examined microRNAs

Overall, 63 out of 503 (12.53\%) tested children were confirmed over several visits to have systolic prehypertension/hypertension, and 58 out of $503(11.53 \%)$ tested children had diastolic prehypertension/hypertension.

No association between the occurrence of prehypertension or hypertension (combined systolic and diastolic prehypertension/hypertension and/or isolated systolic or diastolic prehypertension/hypertension defined as systolic and/or diastolic blood pressures equal or above the 90th or 95th percentiles) and the expression of examined microRNAs was identified in children, regardless of the course of gestation of their mothers.

\subsection{Postnatal Expression Profile of 19 Tested microRNAs Differentiates between Overweight/Obese Children} and Children with Nomal BMI Values

Overall, 32 out of 503 (6.36\%) tested children were confirmed to be overweight/obese.

A total of 19 out of 29 tested microRNAs (miR-1-3p, miR-16-5p, miR-17-5p, miR-21-5p, miR-23a-3p, miR-24-3p, miR-26a-5p, miR-92a-3p, miR-100-5p, miR-103a-3p, miR-125b-5p, miR-126-3p, miR-130b-3p, miR-133a-3p, miR-146a-5p, miR-181a-5p, miR-210-3p, miR-221-3p and miR-574-3p) showed increased expression in overweight/obese children (defined as BMI equal to or above the 85th or 95th percentiles) when the comparison to children with normal BMI values regardless of prenatal and perinatal outcomes was performed. The ROC curve analyses showed that these particular microRNAs differentiated at 10.0\% FPR between overweight/obese children and children with normal BMI values, with a sensitivity ranging from $6.25 \%$ to $31.25 \%$ (Figure S2).

Screening on the base of a combination of these 19 aberrantly expressed microRNAs was superior to single microRNAs. At 10.0\% FPR, $40.63 \%$ overweight/obese children had substantially altered microRNA expression profile, which may contribute to the predisposition to an increased risk of later onset of diabetes mellitus, cardiovascular and cerebrovascular diseases (AUC 0.743, $p<0.001$, sensitivity $65.62 \%$, specificity $76.01 \%$, cut off $>0.060386234$ ) (Figure 2 ).

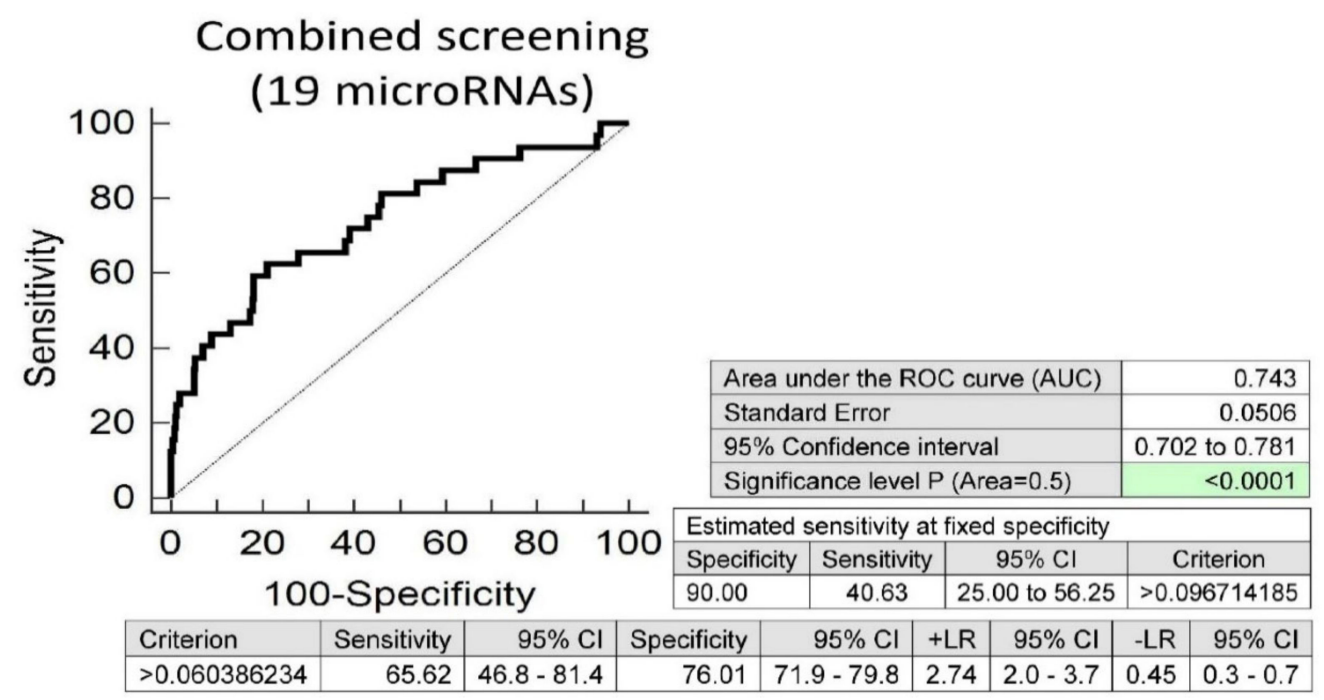

Figure 2. Aberrant microRNA expression profile in overweight/obese children, irrespective of the course of gestation of their mothers (normal and complicated pregnancies altogether). Combined screening revealed that at $10.0 \% \mathrm{FPR}, 40.63 \%$ of overweight/obese children had substantially altered microRNA expression profile (miR-1-3p, miR-16-5p, miR-17-5p, miR-21-5p, miR-23a-3p, miR-24-3p, miR-26a-5p, miR-92a-3p, miR-100-5p, miR-103a-3p, miR-125b-5p, miR-126-3p, miR-130b-3p, miR-133a-3p, miR-146a-5p, miR-181a-5p, miR-210-3p, miR-221-3p and miR-574-3p). 
2.4. Postnatal Expression Profile of 10 Tested microRNAs Differentiates between Children with Abnormal and Normal Values of Echocardiographic Measurements

Overall, 123 out of 503 (24.45\%) tested children were confirmed to have abnormal values of echocardiographic measurements. In detail, children indicated by the sonographer during the visit had the following valve problems and heart defects ((tricuspid valve regurgitation $(n=57 / 503)$, mitral valve regurgitation $(n=5 / 503)$, pulmonary valve regurgitation $(n=22 / 503)$, bicuspid aortic valve regurgitation $(n=2 / 503)$, ventricular septum defect $(n=4 / 503)$, atrial septum defect $(n=3 / 503)$, foramen ovale apertum $(n=40 / 503)$, ductus arteriosus patens $(n=3 / 503)$, and arrhythmia $(n=3 / 503))$.

A total of 10 out of 29 tested microRNAs (miR-1-3p, miR-16-5p, miR-20a-5p, miR-21-5p, miR-125b-5p, miR-126-3p, miR-146a-5p, miR-195-5p, miR-221-3p and miR-499a-5p) showed increased expression in children with valve problems or heart defects when compared to children with normal echocardiographic values, regardless of prenatal and perinatal outcomes. The ROC curve analyses showed that these individual microRNAs differentiated at 10.0\% FPR between children with normal and abnormal values of echocardiographic measurements, with a sensitivity ranging from $10.66 \%$ to $19.67 \%$ (Figure S3).

Screening on the base of a combination of these 10 aberrantly expressed microRNAs showed a slightly higher accuracy than individual microRNAs, with the best performance (miR-21-5p, miR-499a-5p and miR-126-3p). It showed that at $10.0 \%$ FPR, $22.13 \%$ of children with valve problems or heart defects had a substantially altered microRNA expression profile (AUC 0.580, $p=0.0095$, sensitivity $57.38 \%$, specificity $58.97 \%$, cut off $>0.238530721$ ) (Figure 3 ).

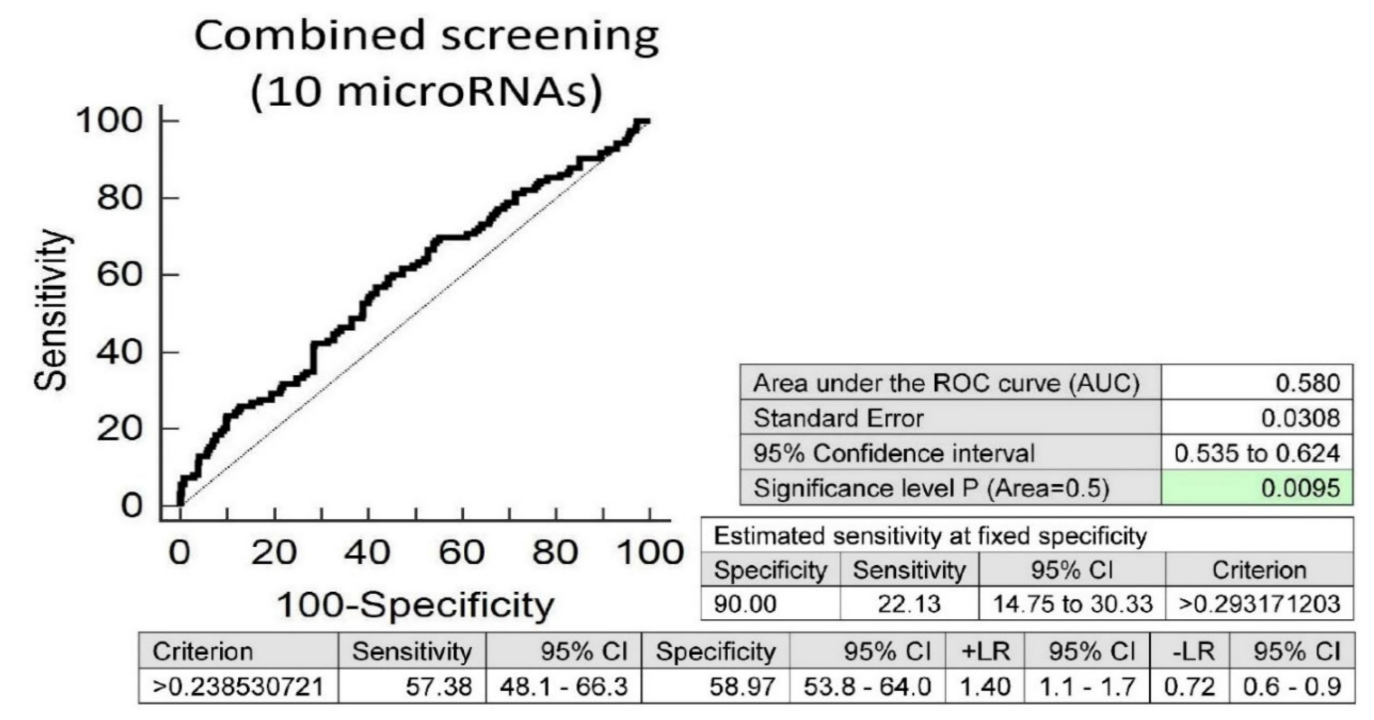

Figure 3. Aberrant microRNA expression profile in children with valve problems or heart defects, irrespective of the course of gestation of their mothers (normal and complicated pregnancies altogether). Combined screening revealed that at $10.0 \%$ FPR, $22.13 \%$ of children with valve problems or heart defects had substantially altered microRNA expression profile (miR-1-3p, miR-16-5p, miR-20a-5p, miR-21-5p, miR-125b-5p, miR-126-3p, miR-146a-5p, miR-195-5p, miR-221-3p and miR-499a-5p).

Nevertheless, with regard to a high number of outliers in children with normal BMI values and in children with normal values of echocardiographic measurements, and with regard to a large impact of the course of gestation of mothers on postnatal microRNA expression profile, we finally decided to also evaluate microRNA expression data within the equal groups of children (children born from normal gestation only, and children born from complicated gestation only). 
2.5. Postnatal Expression Profile of 19 Tested microRNAs Differentiates between Overweight/Obese and Normal Weight Children Born from Normal Pregnancies

Overall, 10 out of $92(10.87 \%)$ tested children born from normal gestation were confirmed to be overweight/obese.

In children born from normal gestation, the expression of microRNAs was significantly different or on a border of significance (miR-16-5p, miR-17-5p, miR-20b-5p, miR-21-5p, miR-23a-3p, miR-24-3p, miR-26a-5p, miR-29a-3p, miR-92a-3p, miR-100-5p, miR-103a-3p, miR-125b-5p, miR-126-3p, miR-130b-3p, miR-145-5p, miR-146a-5p, miR-181a-5p, miR-210-3p and miR-574-3p) in overweight/obese individuals. The ROC curve analyses showed that these individual microRNAs differentiated at $10.0 \%$ FPR between overweight/obese and normal weight children, with a sensitivity ranging from $10.0 \%$ to $40.0 \%$ (Figure S4).

Screening on the base of a combination of all these 19 microRNAs was superior to the performance of single microRNAs, and showed that at $10.0 \%$ FPR, $70.0 \%$ of overweight/obese children born from normal gestation had a substantially altered postnatal microRNA expression profile (AUC 0.895, $p<0.001$, sensitivity $90.0 \%$, specificity $75.6 \%$, cut off $>0.076417901$ ) (Figure 4 ).

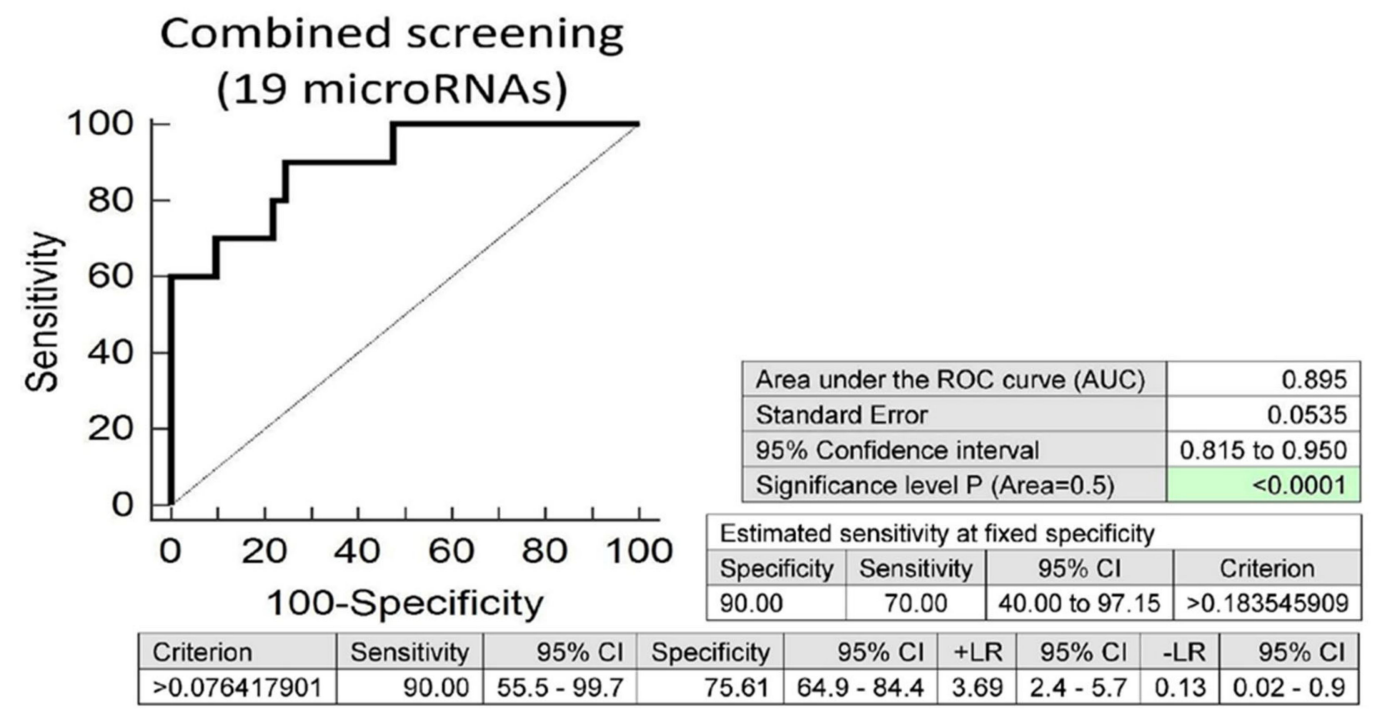

Figure 4. Aberrant microRNA expression profile in overweight/obese children descending from normal pregnancies. Combined screening revealed that at $10.0 \%$ FPR, $70.0 \%$ of overweight/obese children had a substantially altered microRNA expression profile (miR-16-5p, miR-17-5p, miR-20b-5p, miR-21-5p, miR-23a-3p, miR-24-3p, miR-26a-5p, miR-29a-3p, miR-92a-3p, miR-100-5p, miR-103a-3p, miR-125b-5p, miR-126-3p, miR-130b-3p, miR-145-5p, miR-146a-5p, miR-181a-5p, miR-210-3p and miR-574-3p).

2.6. Postnatal Expression Profile of 18 Tested microRNAs Differentiates between Overweight/Obese and Normal Weight Children Born from Complicated Gestation

Overall, 22 out of 411 (5.35\%) tested children born from complicated gestation were confirmed to be overweight/obese.

In children born from complicated gestation, increased expression or a trend towards increased expression (miR-1-3p, miR-16-5p, miR-17-5p, miR-20a-5p, miR-26a-5p, miR-92a-3p, miR-103a-3p, miR-125b-5p, miR-126-3p, miR-130b-3p, miR-133a-3p, miR-146a-5p, miR-181a-5p, miR-195-5p, miR-199a-5p, miR-210-3p, miR-221-3p and miR-499a-5p) was detected in overweight/obese children. The ROC curve analyses showed that these individual microRNAs differentiated at $10.0 \%$ FPR between overweight/obese and normal weight children, with a sensitivity ranging from $9.09 \%$ to $31.82 \%$ (Figure S5).

Screening on the base of a combination of all these 18 microRNAs was superior to the performance of single microRNAs, and showed that at $10.0 \%$ FPR, $42.86 \%$ of overweight/obese children born from 
complicated gestation had a significantly altered postnatal microRNA expression profile (AUC 0.753, $p<0.001$, sensitivity $71.4 \%$, specificity 67.7\%, cut off $>0.038238759$ ) (Figure 5).

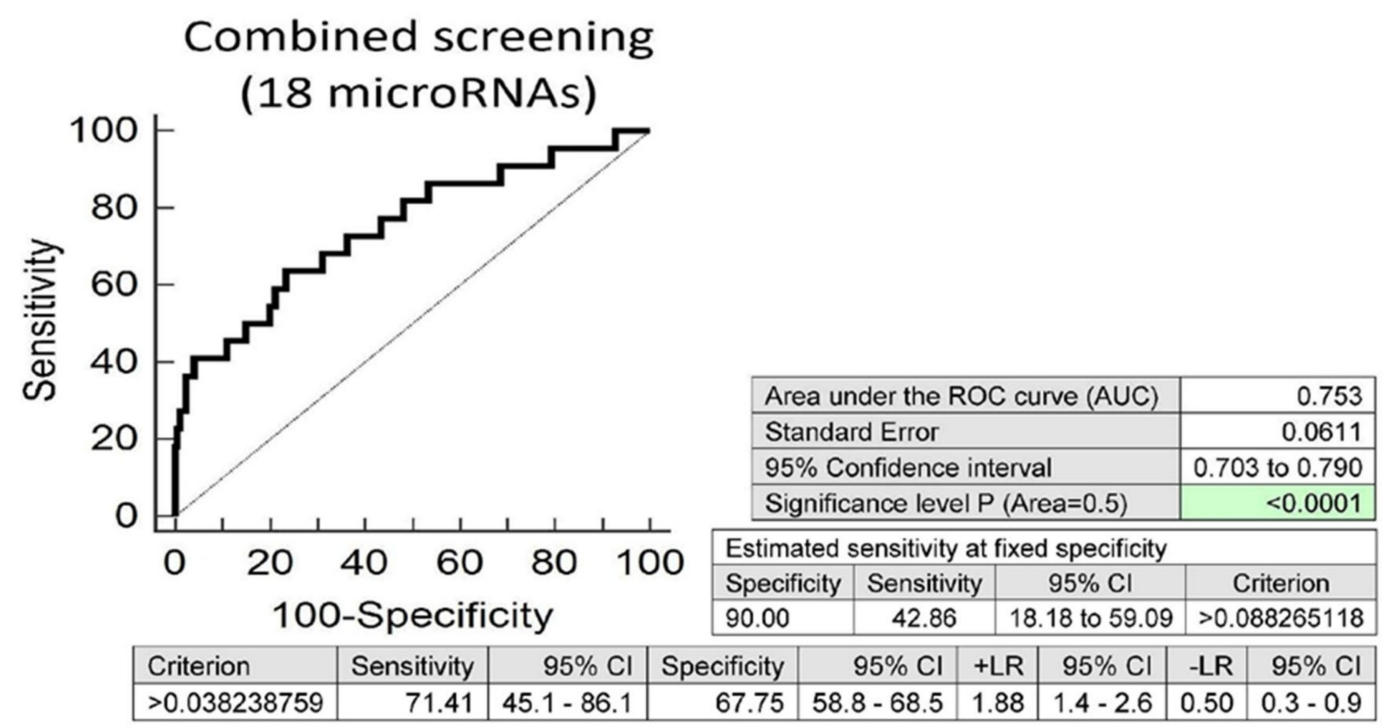

Figure 5. Aberrant microRNA expression profile in overweight/obese children descending from complicated pregnancies. Combined screening revealed that at $10.0 \% \mathrm{FPR}, 42.86 \%$ of overweight/obese children had a substantially altered microRNA expression profile (miR-1-3p, miR-16-5p, miR-17-5p, miR-20a-5p, miR-26a-5p, miR-92a-3p, miR-103a-3p, miR-125b-5p, miR-126-3p, miR-130b-3p, miR-133a-3p, miR-146a-5p, miR-181a-5p, miR-195-5p, miR-199a-5p, miR-210-3p, miR-221-3p and miR-499a-5p).

2.7. Postnatal Expression Profile of 19 microRNAs Differentiates between Children with Abnormal and Normal Values of Echocardiographic Measurements Descending from Complicated Pregnancies

Overall, 106 out of 411 (25.79\%) tested children born from complicated gestation had abnormal values of echocardiographic measurements. In detail, children indicated by the sonographer during the visit had the following valve problems and heart defects ((tricuspid valve regurgitation $(n=49 / 411)$, mitral valve regurgitation $(n=4 / 411)$, pulmonary valve regurgitation $(n=20 / 411)$, bicuspid aortic valve regurgitation $(n=1 / 411)$, ventricular septum defect $(n=3 / 411)$, atrial septum $\operatorname{defect}(n=2 / 411)$, foramen ovale apertum $(n=35 / 411)$, ductus arteriosus patens $(n=3 / 411)$ and arrhythmia $(n=2 / 411))$.

In children born from complicated gestation, the statistical significant difference or difference on a border of significance was detected between individuals with abnormal and normal values of echocardiographic measurements for miR-1-3p, miR-16-5p, miR-17-5p, miR-20a-5p, mir-20b-5p, miR-21-5p, miR-26a-5p, miR-29a-3p, miR-100-5p, miR-125b-5p, miR-126-3p, miR-143-3p, miR-146a-5p, miR-181a-5p, miR-195-5p, miR-221-3p, miR-342-3p, miR-499a-5p and miR-574-3p. The performance of ROC curve analyses revealed that these individual microRNAs differentiated at $10.0 \%$ FPR between children with abnormal and normal values of echocardiographic measurements, with a sensitivity ranging from $11.32 \%$ to $22.64 \%$ (Figure 56 ).

Screening on the base of a combination of all these 19 microRNAs was superior to the performance of single microRNAs, and showed that at $10.0 \%$ FPR, $27.36 \%$ children with valve problems or heart defects born from complicated gestation had significantly altered postnatal microRNA expression profile (AUC 0.641, $p<0.001$, sensitivity 58.49\%, specificity 26.08\%, cut off $>0.258011014$ ) (Figure 6). 


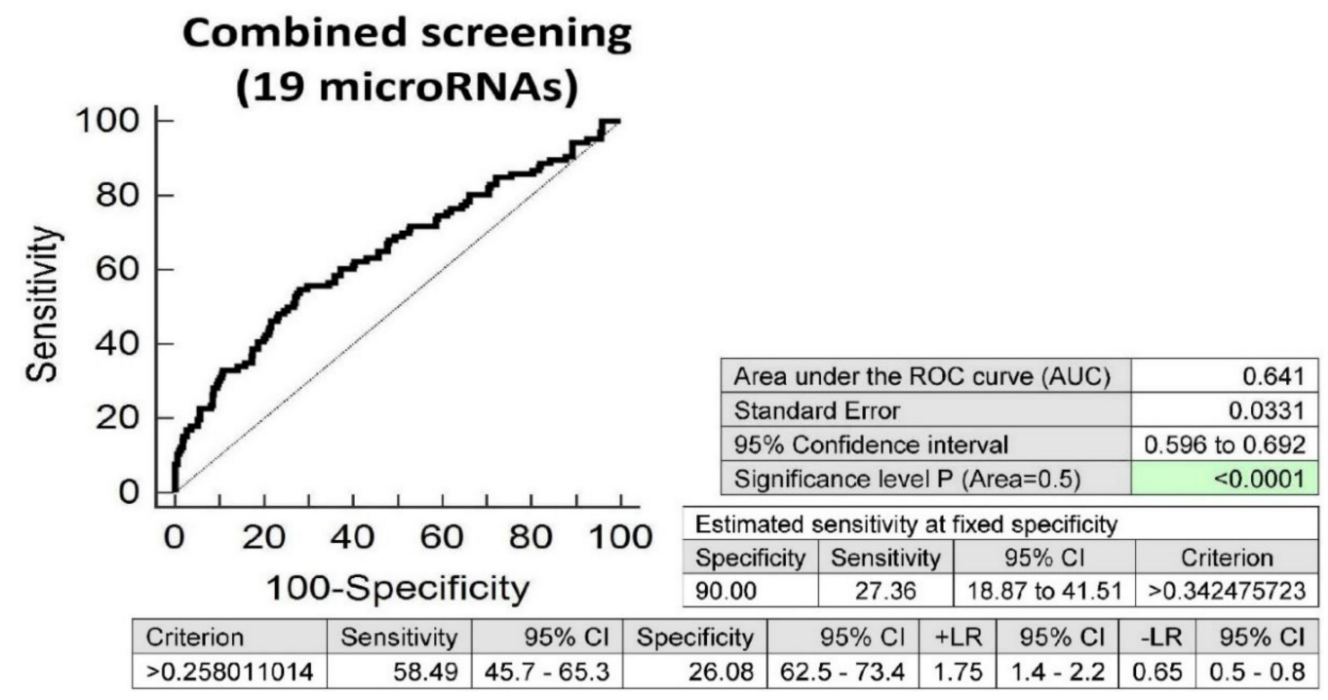

Figure 6. Aberrant microRNA expression profile in children with valve problems or heart defects descending from complicated pregnancies. Combined screening revealed that at $10.0 \%$ FPR, $27.36 \%$ of children with valve problems or heart defects had a substantially altered microRNA expression profile (miR-1-3p, miR-16-5p, miR-17-5p, miR-20a-5p, mir-20b-5p, miR-21-5p, miR-26a-5p, miR-29a-3p, miR-100-5p, miR-125b-5p, miR-126-3p, miR-143-3p, miR-146a-5p, miR-181a-5p, miR-195-5p, miR-221-3p, miR-342-3p, miR-499a-5p and miR-574-3p).

\section{Discussion}

At first, we made comparison of microRNA expression profile between children born from complicated and normal gestation, irrespective of the type of pregnancy-related complication (gestational diabetes mellitus, gestational hypertension, preeclampsia, FGR, preterm prelabor rupture of membranes and/or spontaneous preterm birth). Subsequently, we made a comparison of the microRNA expression profile between particular groups of children with respect to actual findings (normal systolic and diastolic blood pressures vs. prehypertension/hypertension; normal BMI vs. overweight/obesity; normal values of echocardiographic measurements vs. the occurrence of valve problems and/or heart defects), regardless of prenatal and perinatal exposure to pregnancy complications (gestational diabetes mellitus, gestational hypertension, preeclampsia, FGR, preterm prelabor rupture of membranes and/or spontaneous preterm birth). In view of the fact that the prenatal and perinatal exposure to any pregnancy-related complication (gestational diabetes mellitus, gestational hypertension, preeclampsia, FGR, preterm prelabor rupture of membranes and/or spontaneous preterm birth) led to substantial alterations of postnatal microRNA expression profile in a proportion of children, we also compared microRNA expression profile between equal groups of children (children born from normal gestation only and children born from complicated gestation only) with respect to actual findings (the occurrence of overweight, obesity, prehypertension, hypertension, valve problems and heart defects).

Substantially altered microRNA expression profile (23 out of 29 tested microRNAs) was identified in a significant proportion of children $(57.42 \%$ at $10.0 \%$ FPR) born from complicated gestation, when compared with children born from normal gestation. All microRNAs (miR-1-3p, miR-16-5p, miR-17-5p, miR-20a-5p, miR-20b-5p, miR-21-5p, miR-23a-3p, miR-26a-5p, miR-29a-3p, miR-100-5p, miR-103a-3p, miR-125b-5p, miR-126-3p, miR-130b-3p, miR-133a-3p, miR-143-3p, miR-146a-5p, miR-181a-5p, miR-195-5p, miR-199a-5p, miR-221-3p, miR-499a-5p and miR-574-3p) were upregulated in the whole peripheral blood of children prenatally or perinatally affected with pregnancy-related complications. We believe that the early life occurrence of alterations in expression of microRNAs involved in the pathogenesis of diabetes mellitus and diverse cardiovascular and cerebrovascular diseases might originate a solid base for predisposition to later onset of diabetes mellitus, cardiovascular and cerebrovascular diseases. For that reason, we consider children exposed to any type of 
pregnancy-related complication indicated to have altered microRNA expression profile in their peripheral blood leukocytes as the most risky group that should be dispesarized, with the aim of implementing primary prevention measures. Similar findings were reported in children born small for gestational age (SGA), in whom significantly higher circulating levels of miR-16-5p and miR-126-3p were observed in serum samples at the age of 9 years [54].

Parallel to this, we could see that the presence of overweight/obesity and/or valve problems and heart defects had an additional impact on already altered microRNA expression profile in a group of children affected with pregnancy-related complications. A significant proportion of overweight/obese children ( $42.86 \%$ at $10.0 \%$ FPR) and children with valve problems and heart defects ( $27.36 \%$ at $10.0 \%$ FPR) born from complicated gestation had even higher microRNA expression levels than children from the equal group with actual normal findings. Overweight/obesity intensified upregulation of multiple microRNAs (miR-1-3p, miR-16-5p, miR-17-5p, miR-20a-5p, miR-26a-5p, miR-103a-3p, miR-125b-5p, miR-126-3p, miR-130b-3p, miR-133a-3p, miR-146a-5p, miR-181a-5p, miR-195-5p, miR-199a-5p, miR-221-3p and miR-499a-5p) already present in a group of children previously affected with pregnancy complications. The presence of overweight/obesity induced upregulation of miR-92a-3p and miR-210-3p in children born from complicated gestation. Similarly, abnormal values of echocardiographic measurements also heighten upregulation of some microRNAs, which had already shown altered expression (miR-1-3p, miR-16-5p, miR-17-5p, miR-20a-5p, miR-20b-5p, miR-21-5p, miR-26a-5p, miR-29a-3p, miR-100-5p, miR-125b-5p, miR-126-3p, miR-143-3p, miR-146a-5p, miR-181a-5p, miR-195-5p, miR-221-3p, miR-499a-5p and miR-574-3p) in a group of children prenatally or perinatally affected with pregnancy-related complications. The presence of valve problems and heart defects induced upregulation of miR-342-3p in a group of children born from complicated gestation.

Interestingly, microRNA expression profiles were also able to differentiate between children with abnormal and normal findings (BMI) born from normal gestation. Similarly, as in children born from complicated gestation, the upregulation of multiple microRNAs (miR-16-5p, miR-17-5p, miR-26a-5p, miR-103a-3p, miR-125b-5p, miR-126-3p, miR-130b-3p, miR-146a-5p and miR-181a-5p) was detected in overweight/obese children. In addition, the overweight/obesity induced upregulation of other microRNAs (miR-20b-5p, miR-21-5p, miR-23a-3p, miR-24-3p, miR-29a-3p, miR-92a-3p, miR-100-5p, miR-145-5p, miR-210-3p and miR-574-3p) in children born from normal gestation. Overall, at $10.0 \%$ FPR $70.0 \%$, overweight/obese children born from normal gestation demonstrated this abnormal expression profile in their whole peripheral blood. On the other hand, the presence of valve problems or heart defects in children born from normal gestation did not induce any alterations in microRNA gene expression. However, this finding might be influenced by a low number of children with abnormal findings (the occurrence of valve problems or heart defects) in children born from normal gestation.

Differentiation between children with abnormal and normal findings (overweight/obesity, the occurrence of valve problems or heart defects) is also feasible, irrespective of a history of the course of maternal gestation. We identified that at $10.0 \%$ FPR, a significant proportion of overweight and obese children $(40.63 \%)$ had a substantially altered microRNA expression profile. A total of 19 out of 29 tested microRNAs (miR-1-3p, miR-16-5p, miR-17-5p, miR-21-5p, miR-23a-3p, miR-24-3p, miR-26a-5p, miR-92a-3p, miR-100-5p, miR-103a-3p, miR-125b-5p, miR-126-3p, miR-130b-3p, miR-133a-3p, miR-146a-5p, miR-181a-5p, miR-210-3p, miR-221-3p and miR-574-3p) showed increased expression in overweight/obese children. MicroRNA expression alterations of less extent (miR-1-3p, miR-16-5p, miR-20a-5p, miR-21-5p, miR-125b-5p, miR-126-3p, miR-146a-5p, miR-195-5p, miR-221-3p and miR-499a-5p) were also detected in a proportion of children $(22.13 \%)$ with valve problems or heart defects. Nevertheless, from the data resulting from this study, it is apparent, that the evaluation of potential cardiovascular risk based on the presence of aberrant microRNA expression profile in peripheral blood leukocytes is more accurate with the knowledge of a history of the course of maternal gestation, which might significantly contribute to postnatal modifications of microRNA expression profiles in peripheral blood leukocytes. 
Our data may be supported by the data of Chen et al. [55], who recently reported that miR-17-5p is, together with miR-27a/b, a key microRNA playing a role in the pathogenesis of childhood obesity via the regulation of the NLK and RRAS2 genes. Nevertheless, this study was performed using different methodological approach, tissue samples were analyzed using microarray methodology. Similarly, our data are compliant with the data of other investigators, who reported that miR-103a-3p is one of microRNAs implicated in appetite and energy balance control affecting overeating during obesity development including children as well [56,57]. Likewise, Marzano et al. [58] observed upregulation of circulating (serum) miR-92a-3p in obese children, regardless of whether they had been born small for gestational age or appropriate for gestational age.

Circulating (plasma) miR-342-3p was reported, until now, to be associated just with endothelial dysfunction in children, not with other cardiovascular risk factors or other abnormal clinical findings, which is in agreement with our data, even though plasma and whole peripheral blood microRNA gene expression profiles may have different patterns [59].

\section{Materials and Methods}

\subsection{Participants}

The study of a prospective design running within the period of 8/2016-10/2020 involved children of Caucasian descent at the age of 3 to 11 years born from normal pregnancies $(n=92)$ and pregnancies complicated with gestational diabetes mellitus $(n=118)$, gestational hypertension $(n=53)$, preeclampsia $(n=135)$, fetal growth restriction $(n=35)$, preterm prelabor rupture of membranes or spontaneous preterm birth $(n=70)$. The data of children born from normal and complicated gestation are presented in Table 1.

Normal gestation was reported as that one without medical, obstetrical, or surgical complications, where healthy infants with the weight $>2500 \mathrm{~g}$ were born after 37 weeks of gestation $[52,53]$.

Gestational diabetes mellitus, glucose intolerance during gestation, was diagnosed following the recommendations of the International Association of Diabetes and Pregnancy Study Groups (IADPSG) [53,60].

Gestational hypertension, hypertension $(>140 / 90 \mathrm{mmHg}$ ) with no sign of proteinuria with the first onset after 20 weeks of gestation, was diagnosed following the recommendations of American College of Obstetricians and Gynecologists (ACOG) [52,61].

Preeclampsia was characterized as the occurrence of hypertension and proteinuria ( $>300 \mathrm{mg} / 24 \mathrm{~h}$ ) that appeared firstly after 20 weeks of gestation $[52,61]$. The severity of preeclampsia was assessed following the recommendations of ACOG [52,61].

FGR, the estimated fetal weight (EFW) below the 3rd percentile or below the 10th percentile for the evaluated gestational age, early FGR (before 32 week of gestation), and late FGR (after 32 week of gestation) were diagnosed based on the current recommendations [52,62-64].

Preterm birth (PTB) was defined as the delivery before 37 weeks of gestation at the occurrence of regular uterine contractions along with cervical changes. Preterm prelabor rupture of membranes (PPROM) was diagnosed when amniotic fluid leakage preceded the onset of labor by at least $2 \mathrm{~h} \mathrm{[65-67].} \mathrm{The} \mathrm{exclusion} \mathrm{criteria} \mathrm{for} \mathrm{preterm} \mathrm{birth} \mathrm{(PTB} \mathrm{or} \mathrm{PPROM)} \mathrm{included} \mathrm{gestational}$ hypertension, preeclampsia, gestational diabetes mellitus, significant vaginal bleeding and signs of fetal growth restriction.

More details on the definition of individual pregnancy complications are also available in Supplementary Materials.

Children with inborn defects, chromosomal abnormalities and children born from gestation with other complications were excluded from the study. 
Table 1. Characteristics of cases and controls.

\begin{tabular}{|c|c|c|c|c|c|c|c|c|c|c|c|c|c|}
\hline & $\begin{array}{c}\mathrm{NP} \\
(n=92)\end{array}$ & $\begin{array}{c}\text { PE } \\
(n=135)\end{array}$ & $\begin{array}{c}\text { FGR } \\
(n=35)\end{array}$ & $\begin{array}{c}\text { GH } \\
(n=53)\end{array}$ & $\begin{array}{c}\text { GDM } \\
(n=118)\end{array}$ & $\begin{array}{c}\text { PTB } \\
(n=33)\end{array}$ & $\begin{array}{c}\text { PPROM } \\
(n=37)\end{array}$ & $p$-Value $^{1}$ & $p$-Value ${ }^{2}$ & $p$-Value ${ }^{3}$ & $p$-Value ${ }^{4}$ & $p$-Value ${ }^{5}$ & $p$-Value ${ }^{6}$ \\
\hline \multicolumn{14}{|c|}{ At follow-up } \\
\hline Age (years) & $5(3-11)$ & $5(3-11)$ & $4(3-10)$ & $5(3-10)$ & $5(3-10)$ & $5(3-8)$ & $5(3-9)$ & 1.000 & 0.302 & 1.000 & 1.000 & 1.000 & 1.000 \\
\hline Height $(\mathrm{cm})$ & $\begin{array}{c}116.5 \\
(98-153) \\
\end{array}$ & $\begin{array}{c}114.0 \\
(97-155) \\
\end{array}$ & $\begin{array}{c}106.0 \\
(93-152)\end{array}$ & $\begin{array}{c}112.0 \\
(96-159.5)\end{array}$ & $\begin{array}{c}113.75 \\
(98-153)\end{array}$ & $\begin{array}{c}115.0 \\
(101-138)\end{array}$ & $\begin{array}{c}113.5 \\
(102-145)\end{array}$ & 1.000 & $<0.001$ & 1.000 & 1.000 & 1.000 & 1.000 \\
\hline Weight (kg) & $\begin{array}{c}21.25 \\
14-40.8)\end{array}$ & $\begin{array}{c}19.25 \\
(11.85-54.9)\end{array}$ & $\begin{array}{c}16.00 \\
(12-37)\end{array}$ & $\begin{array}{c}19.70 \\
(14-47.5)\end{array}$ & $\begin{array}{c}19.50 \\
(14.4-47.1)\end{array}$ & $\begin{array}{c}19.70 \\
(14.1-29.6)\end{array}$ & $\begin{array}{c}20.20 \\
(14.7-47.9)\end{array}$ & 0.331 & $<0.001$ & 1.000 & 1.000 & 1.000 & 1.000 \\
\hline $\operatorname{BMI}\left(\mathrm{kg} / \mathrm{m}^{2}\right)$ & $\begin{array}{c}15.54 \\
(13.22-20)\end{array}$ & $\begin{array}{c}14.90 \\
(12.34-22.81)\end{array}$ & $\begin{array}{c}14.24 \\
(12.7-19.24)\end{array}$ & $\begin{array}{c}15.42 \\
(13.42-19.7)\end{array}$ & $\begin{array}{c}15.32 \\
(12.97-20.08)\end{array}$ & $\begin{array}{c}14.75 \\
(12.09-19.89)\end{array}$ & $\begin{array}{c}15.86 \\
(13.23-26.28)\end{array}$ & 0.399 & $<0.001$ & 1.000 & 1.000 & 0.461 & 1.000 \\
\hline $\begin{array}{c}\text { Systolic BP } \\
\text { (mmHg) }\end{array}$ & $\begin{array}{c}100.5 \\
(84-123)\end{array}$ & $\begin{array}{c}99 \\
(84-132)\end{array}$ & $\begin{array}{c}97 \\
(82-123)\end{array}$ & $\begin{array}{c}99 \\
(80-129)\end{array}$ & $\begin{array}{c}100 \\
(82-125)\end{array}$ & $\begin{array}{c}100 \\
(87-118)\end{array}$ & $\begin{array}{c}102 \\
(88-125)\end{array}$ & 1.000 & 0.812 & 1.000 & 1.000 & 1.000 & 1.000 \\
\hline Diastolic BP (mmHg) & $\begin{array}{c}61 \\
(38-81)\end{array}$ & $\begin{array}{c}61 \\
(41-88)\end{array}$ & $\begin{array}{c}60 \\
(42-73)\end{array}$ & $\begin{array}{c}62 \\
(49-83)\end{array}$ & $\begin{array}{c}61 \\
(64-122)\end{array}$ & $\begin{array}{c}61 \\
(43-72)\end{array}$ & $\begin{array}{c}64 \\
(48-76)\end{array}$ & 1.000 & 1.000 & 1.000 & 1.000 & 1.000 & 1.000 \\
\hline Heart rate $(\mathrm{n} / \mathrm{min})$ & $\begin{array}{c}90 \\
(51-120) \\
\end{array}$ & $\begin{array}{c}92 \\
(64-117) \\
\end{array}$ & $\begin{array}{c}95.5 \\
(62-112) \\
\end{array}$ & $\begin{array}{c}94 \\
(65-129) \\
\end{array}$ & $\begin{array}{c}97 \\
(64-122) \\
\end{array}$ & $\begin{array}{c}95 \\
(76-120) \\
\end{array}$ & $\begin{array}{c}96 \\
(74-114) \\
\end{array}$ & 1.000 & 1.000 & 1.000 & 0.002 & 0.331 & 0.551 \\
\hline \multicolumn{14}{|c|}{ Abnormal echocardiographic findings } \\
\hline Yes & $17(18.48 \%)$ & $18(13.33 \%)$ & $9(25.71 \%)$ & $12(22.64 \%)$ & $42(35.59 \%)$ & $10(30.30 \%)$ & $15(40.54 \%)$ & 0.292 & 0.367 & 0.546 & 0.006 & 0.157 & 0.009 \\
\hline No & $75(81.52 \%)$ & $\begin{array}{c}117 \\
(86.66 \%)\end{array}$ & $26(74.29 \%)$ & $41(77.36 \%)$ & $76(64.41 \%)$ & $23(69.70 \%)$ & $22(59.46 \%)$ & & & & & & \\
\hline \multicolumn{14}{|c|}{ During gestation } \\
\hline $\begin{array}{l}\text { Maternal age at delivery } \\
\text { (years) }\end{array}$ & $\begin{array}{c}32 \\
(20-46)\end{array}$ & $\begin{array}{c}32 \\
(21-44)\end{array}$ & $\begin{array}{c}32 \\
(22-41)\end{array}$ & $\begin{array}{c}32 \\
(27-51)\end{array}$ & $\begin{array}{c}34 \\
(27-45)\end{array}$ & $\begin{array}{c}32 \\
(20-39)\end{array}$ & $\begin{array}{c}32 \\
(22-42)\end{array}$ & 1.000 & 1.000 & 1.000 & 0.569 & 1.000 & 1.000 \\
\hline GA at delivery (weeks) & $\begin{array}{c}39.86 \\
(37.71-41.86)\end{array}$ & $\begin{array}{c}35.86 \\
(26-41.72)\end{array}$ & $\begin{array}{c}35.14 \\
(28-41)\end{array}$ & $\begin{array}{c}38.68 \\
(33.43-41.28)\end{array}$ & $\begin{array}{c}39.57 \\
(37-41.18)\end{array}$ & $\begin{array}{c}31.0 \\
(24-36.43)\end{array}$ & $\begin{array}{c}33.43 \\
(24.71-35.86)\end{array}$ & $<0.001$ & $<0.001$ & 0.002 & 1.000 & $<0.001$ & $<0.001$ \\
\hline \multicolumn{14}{|c|}{ Mode of delivery } \\
\hline Vaginal & $81(88.04 \%)$ & $15(11.11 \%)$ & $6(17.14 \%)$ & $24(45.28 \%)$ & $75(63.56 \%)$ & $23(69.70 \%)$ & $17(45.95 \%)$ & \multirow[t]{2}{*}{$<0.001$} & \multirow[t]{2}{*}{$<0.001$} & \multirow[t]{2}{*}{$<0.001$} & \multirow[t]{2}{*}{$<0.001$} & \multirow[t]{2}{*}{0.016} & \multirow[t]{2}{*}{$<0.001$} \\
\hline CS & $11(11.96 \%)$ & $\begin{array}{c}120 \\
(88.88 \%)\end{array}$ & $29(82.86 \%)$ & $29(54.72 \%)$ & $43(36.44 \%)$ & $10(30.30 \%)$ & $20(54.05 \%)$ & & & & & & \\
\hline Fetal birth weight (g) & $\begin{array}{c}3410 \\
(2530-4450)\end{array}$ & $\begin{array}{c}2360 \\
(660-4490)\end{array}$ & $\begin{array}{c}1630 \\
(650-3010)\end{array}$ & $\begin{array}{c}3150 \\
(1940-4310)\end{array}$ & $\begin{array}{c}3485 \\
(2700-4400)\end{array}$ & $\begin{array}{c}1570 \\
(542-2820)\end{array}$ & $\begin{array}{c}2100 \\
(600-2710)\end{array}$ & $<0.001$ & $<0.001$ & 0.318 & 1.000 & $<0.001$ & $<0.001$ \\
\hline \multicolumn{14}{|c|}{ Fetal sex } \\
\hline Boy & $47(51.09 \%)$ & $57(42.22 \%)$ & 18 (51.43\%) & $26(49.06 \%)$ & $74(62.71 \%)$ & $20(60.60 \%)$ & $15(40.54 \%)$ & \multirow{2}{*}{0.188} & \multirow{2}{*}{0.973} & \multirow{2}{*}{0.814} & \multirow{2}{*}{0.091} & \multirow{2}{*}{0.347} & \multirow{2}{*}{0.278} \\
\hline Girl & $45(48.91 \%)$ & 78 (57.77\%) & $17(48.57 \%)$ & 27 (50.94\%) & $44(37.29 \%)$ & $13(39.40 \%)$ & $22(59.46 \%)$ & & & & & & \\
\hline
\end{tabular}


Table 1. Cont.

\begin{tabular}{|c|c|c|c|c|c|c|c|c|c|c|c|c|c|}
\hline & $\begin{array}{c}\mathrm{NP} \\
(n=92)\end{array}$ & $\begin{array}{c}\text { PE } \\
(n=135)\end{array}$ & $\begin{array}{c}\text { FGR } \\
(n=35)\end{array}$ & $\begin{array}{c}\text { GH } \\
(n=53)\end{array}$ & $\begin{array}{c}\text { GDM } \\
(n=118)\end{array}$ & $\begin{array}{c}\text { PTB } \\
(n=33)\end{array}$ & $\begin{array}{c}\text { PPROM } \\
(n=37)\end{array}$ & $p$-Value ${ }^{1}$ & $p$-Value ${ }^{2}$ & $p$-Value ${ }^{3}$ & $p$-Value ${ }^{4}$ & $p$-Value ${ }^{5}$ & $p$-Value ${ }^{6}$ \\
\hline \multicolumn{14}{|c|}{ Primiparity } \\
\hline Yes & $49(53.26 \%)$ & $\begin{array}{c}109 \\
(80.74 \%)\end{array}$ & $34(97.14 \%)$ & $36(67.92 \%)$ & $54(45.76 \%)$ & $23(69.70 \%)$ & $28(75.68 \%)$ & \multirow[t]{2}{*}{$<0.001$} & \multirow[t]{2}{*}{$<0.001$} & \multirow[t]{2}{*}{0.084} & \multirow{2}{*}{0.281} & \multirow[t]{2}{*}{0.101} & \multirow{2}{*}{0.019} \\
\hline No & $43(46.74 \%)$ & $26(19.26 \%)$ & $1(2.86 \%)$ & $17(32.08 \%)$ & 64 (54.24\%) & $10(30.30 \%)$ & $9(24.32 \%)$ & & & & & & \\
\hline \multicolumn{14}{|c|}{ Birth order of index pregnancy } \\
\hline 1st & $39(42.39 \%)$ & 87 (64.44\%) & 29 (82.86\%) & $28(52.83 \%)$ & $42(35.59 \%)$ & $14(42.42 \%)$ & $17(45.95 \%)$ & \multirow{4}{*}{0.007} & \multirow{4}{*}{$<0.001$} & \multirow{4}{*}{0.471} & \multirow{4}{*}{0.179} & \multirow{4}{*}{0.202} & \multirow{4}{*}{0.790} \\
\hline 2nd & $34(36.96 \%)$ & $28(20.74 \%)$ & $2(5.71 \%)$ & $13(24.53 \%)$ & $45(38.14 \%)$ & $9(27.27 \%)$ & $12(32.43 \%)$ & & & & & & \\
\hline $3 r d$ & $15(16.30 \%)$ & $13(9.63 \%)$ & $2(5.71 \%)$ & $9(16.98 \%)$ & $16(13.56 \%)$ & $5(15.15 \%)$ & $5(13.51 \%)$ & & & & & & \\
\hline 4 th + & $4(4.35 \%)$ & $7(5.19 \%)$ & $2(5.71 \%)$ & $3(5.66 \%)$ & $15(12.71 \%)$ & $5(15.15 \%)$ & $3(8.11 \%)$ & & & & & & \\
\hline \multicolumn{14}{|c|}{ Infertility treatment } \\
\hline Yes & $3(3.26 \%)$ & $34(25.19 \%)$ & $9(25.71 \%)$ & $7(13.21 \%)$ & $16(13.56 \%)$ & $4(12.12 \%)$ & $6(16.22 \%)$ & \multirow{2}{*}{$<0.001$} & \multirow{2}{*}{$<0.001$} & \multirow{2}{*}{0.023} & \multirow{2}{*}{0.010} & \multirow{2}{*}{0.058} & \multirow{2}{*}{0.009} \\
\hline No & $89(96.74 \%)$ & $\begin{array}{c}101 \\
(74.81 \%)\end{array}$ & $26(74.29 \%)$ & $46(86.79 \%)$ & $102(86.44 \%)$ & $29(87.88 \%)$ & $31(83.78 \%)$ & & & & & & \\
\hline
\end{tabular}

Data are presented as median (range) for continuous variables and as number (percent) for categorical variables. Significant results are in bold. Continuous variables were compared using the Kruskal-Wallis test. Categorical variables were compared using a chi-square test. $p$-value ${ }^{1}$ : the comparison between normal gestation and PE; $p$-value ${ }^{2}$ : the comparison between normal gestation and FGR; $p$-value ${ }^{3}$ : the comparison between normal gestation and GH; $p$-value ${ }^{4}$ : the comparison between normal gestation and GDM; $p$-value ${ }^{5}$ : the comparison between normal gestation and PTB; $p$-value ${ }^{6}$ : the comparison between normal gestation and PPROM. NP, normal pregnancies; PE, preeclampsia; FGR, fetal growth restriction; GH, gestational hypertension; GDM, gestational diabetes mellitus; PTB, preterm birth; PPROM, preterm prelabor rupture of membranes; BP, blood pressure; CS, Caesarean section; GA, gestational age. 
Informed consent was gained from all study participants. Two ethics committees (with headquarters in the Institute for the Care of the Mother and Child, and the Third Faculty of Medicine, Charles University) granted the approval with the study (grant no. AZV 16-27761A, long-term monitoring of complex cardiovascular profile in the mother, fetus and offspring descending from pregnancy-related complications, dates of approval: 27.3.2014 and 28.5.2015). All procedures were in agreement with the Helsinki Declaration of 1975, as revised in 2000.

\subsection{Blood Pressure and Echocardiography Measurements, and Body Mass Index Assessment}

Standardized blood pressure (BP) and echocardiography measurements and BMI assessment were performed as previously described [52,53,68]. More details are also available in Supplementary Materials.

\subsection{Processing of Samples, Reverse Transcription, and Relative Quantification of microRNAs}

Processing of samples, reverse transcription and relative quantification of microRNAs were performed as previously described [52,53,69,70]. More details are also available in Supplementary Materials.

\subsection{Statistical Analysis}

Statistical analyses (the Shapiro-Wilk test, Mann-Whitney test (M-W), receivers operating characteristic (ROC) curves, and logistic regression combined with ROC curve analysis) were performed as previously described [52,53,71]. The box plots of log-normalized gene expression values (RT-qPCR expression, $\log _{10} 2^{-\Delta \Delta \mathrm{Ct}}$ ) for particular microRNAs are presented. More details concerning statistical analyses and graphical processing are also available in Supplementary Materials.

\section{Conclusions}

In conclusion, representative microRNA expression profiles for diabetes mellitus, cardiovascular and cerebrovascular diseases may also be detected in peripheral blood leukocytes of children born from complicated gestation (gestational diabetes mellitus, gestational hypertension, preeclampsia, FGR, preterm prelabor rupture of membranes and/or spontaneous preterm birth). This observation implies that pregnancy-related complications of the mother, regardless of its type, may contribute to the predisposition of affected children to later onset of diabetes mellitus, cardiovascular and cerebrovascular diseases. The presence of overweight/obesity and/or valve problems and heart defects have an additional impact on already altered microRNA expression profile in a group of children previously exposed to pregnancy-related complications. MicroRNA expression profiles are also able to differentiate between children with abnormal and normal findings (BMI) born from normal gestation. Consecutive studies are required to confirm the findings of this study.

\section{Patents}

National Patent n. 308102, Industrial Property Office, Czech Republic. PCT/CZ2019/050050, Industrial Property Office, Czech Republic.

Supplementary Materials: Supplementary Materials can be found at http://www.mdpi.com/1422-0067/21/21/ 8413/s1. Figure S1: Aberrant microRNA expression profile in children descending from complicated pregnancies irrespective of the type of pregnancy-related complication (gestational diabetes mellitus, gestational hypertension, preeclampsia, fetal growth restriction, preterm prelabor rupture of membranes, and/or spontaneous preterm birth).; Figure S2: Aberrant microRNA expression profile in overweight/obese children irrespective of the course of gestation of their mothers (normal and complicated pregnancies altogether).; Figure S3: Aberrant microRNA expression profile in children with valve problems or heart defects irrespective of the course of gestation of their mothers (normal and complicated pregnancies altogether).; Figure S4: Aberrant microRNA expression profile in overweight/obese children descending from normal pregnancies.; Figure S5: Aberrant microRNA expression profile in overweight/obese children descending from complicated pregnancies.; Figure S6: Aberrant microRNA expression profile in children with valve problems or heart defects descending from 
complicated pregnancies.; Table S1: The role of studied microRNAs in the pathogenesis of diabetes mellitus and cardiovascular/cerebrovascular diseases.; Supplementary Material-Methods.

Author Contributions: Conceptualization, I.H. and L.K.; methodology, I.H., K.K. and L.K.; software, I.H., K.K., J.S.; validation, I.H., L.K. and J.S.; formal analysis, I.H., K.K.; investigation, K.K. and J.S.; resources, L.K.; data curation, I.H. and K.K.; writing — original draft preparation, I.H., K.K. and J.S.; writing-review and editing, I.H. and K.K.; visualization, K.K.; supervision, I.H. and L.K.; project administration, I.H. and L.K.; funding acquisition, I.H. and L.K. All authors have read and agreed to the published version of the manuscript.

Funding: This research was funded by the Agency of Medical Research, Ministry of Health, Prague, Czech Republic, grant number AZV 16-27761A and by the Charles University, Prague, Czech Republic, grant number 260529/SVV/2020 and PROGRES Q34. All rights reserved.

Acknowledgments: We thank to Jana Kumprichtova, and Sarka Stranska for assistance with collection of biological samples of children.

Conflicts of Interest: The authors have no conflict of interest.

\section{Abbreviations}

$\begin{array}{ll}\text { GDM } & \text { Gestational diabetes mellitus } \\ \text { PE } & \text { Preeclampsia } \\ \text { FGR } & \text { Fetal growth restriction } \\ \text { GH } & \text { Gestational hypertension } \\ \text { AUC } & \text { Area under the Curve } \\ \text { ROC } & \text { Receive Operating Characteristic } \\ \text { FPR } & \text { False Positive Rate } \\ \text { CI } & \text { Confidence Interval } \\ \text { LR+ } & \text { Positive Likelihood Ratio } \\ \text { LR- } & \text { Negative Likelihood Ratio } \\ \text { NP } & \text { Normal Pregnancies } \\ \text { BP } & \text { Blood Pressure } \\ \text { OGTT } & \text { Oral glucose tolerance test } \\ \text { IADPSG } & \text { International Association of Diabetes and Pregnancy Study Groups } \\ \text { BMI } & \text { Body Mass Index } \\ \text { SBP } & \text { Systolic Blood Pressure } \\ \text { DBP } & \text { Diastolic Blood Pressure } \\ \text { GA } & \text { Gestational age } \\ \text { CS } & \text { Caesarean Section }\end{array}$

\section{References}

1. Davis, E.F.; Lazdam, M.; Lewandowski, A.J.; Worton, S.A.; Kelly, B.; Kenworthy, Y.; Adwani, S.; Wilkinson, A.R.; McCormick, K.; Sargent, I.; et al. Cardiovascular Risk Factors in Children and Young Adults Born to Preeclamptic Pregnancies: A Systematic Review. Pediatrics 2012, 129, e1552-e1561. [CrossRef] [PubMed]

2. Alsnes, I.V.; Vatten, L.J.; Fraser, A.; Bjørngaard, J.H.; Rich-Edwards, J.; Romundstad, P.R.; Asvold, B.O. Hypertension in Pregnancy and Offspring Cardiovascular Risk in Young Adulthood. Hypertension 2017, 69, 591-598. [CrossRef] [PubMed]

3. Kawasaki, M.; Arata, N.; Miyazaki, C.; Mori, R.; Kikuchi, T.; Ogawa, Y.; Ota, E. Obesity and abnormal glucose tolerance in offspring of diabetic mothers: A systematic review and meta-analysis. PLoS ONE 2018, 13, e0190676. [CrossRef] [PubMed]

4. Hammoud, N.M.; Visser, G.H.A.; Van Rossem, L.; Biesma, D.H.; Wit, J.M.; De Valk, H.W. Long-term BMI and growth profiles in offspring of women with gestational diabetes. Diabetologia 2018, 61, 1037-1045. [CrossRef] [PubMed]

5. Bianco, M.E.; Josefson, J.L. Hyperglycemia During Pregnancy and Long-Term Offspring Outcomes. Curr. Diabetes Rep. 2019, 19, 143. [CrossRef] 
6. Lee, H.; Jang, H.C.; Park, H.K.; Cho, N.H. Early manifestation of cardiovascular disease risk factors in offspring of mothers with previous history of gestational diabetes mellitus. Diabetes Res. Clin. Pr. 2007, 78, 238-245. [CrossRef]

7. Tam, W.H.; Ma, R.C.W.; Ozaki, R.; Li, A.M.; Chan, M.H.M.; Yuen, L.Y.; Lao, T.T.H.; Yang, X.; Ho, C.S.; Tutino, G.E.; et al. In Utero Exposure to Maternal Hyperglycemia Increases Childhood Cardiometabolic Risk in Offspring. Diabetes Care 2017, 40, 679-686. [CrossRef]

8. Tsadok, M.A.; Friedlander, Y.; Paltiel, O.; Manor, O.; Meiner, V.; Hochner, H.; Sagy, Y.; Sharon, N.; Yazdgerdi, S.; Siscovick, D.; et al. Obesity and Blood Pressure in 17-Year-Old Offspring of Mothers with Gestational Diabetes: Insights from the Jerusalem Perinatal Study. Exp. Diabetes Res. 2011, 2011, 1-6. [CrossRef]

9. Chen, Y.-L.; Han, L.-L.; Shi, X.-L.; Su, W.-J.; Liu, W.; Wang, L.-Y.; Huang, P.-Y.; Lin, M.-Z.; Song, H.-Q.; Li, X. Adverse pregnancy outcomes on the risk of overweight offspring: A population-based retrospective study in Xiamen, China. Sci. Rep. 2020, 10, 1549. [CrossRef]

10. Josefson, J.L.; Catalano, P.M.; Lowe, W.L.; Scholtens, D.M.; Kuang, A.; Dyer, A.R.; Lowe, L.P.; Metzger, B.E. The Joint Associations of Maternal BMI and Glycemia with Childhood Adiposity. J. Clin. Endocrinol. Metab. 2020, 105, 2177-2188. [CrossRef]

11. Liang, Z.; Liu, H.; Wang, L.; Song, Q.; Sun, D.; Li, W.; Leng, J.; Gao, R.; Hu, G.; Qi, L. Maternal Gestational Diabetes Mellitus Modifies the Relationship between Genetically Determined Body Mass Index during Pregnancy and Childhood Obesity. Mayo Clin. Proc. 2020, 95, 1877-1887. [CrossRef] [PubMed]

12. Tenhola, S.; Rahiala, E.; Martikainen, A.; Halonen, P.; Voutilainen, R. Blood Pressure, Serum Lipids, Fasting Insulin, and Adrenal Hormones in 12-Year-Old Children Born with Maternal Preeclampsia. J. Clin. Endocrinol. Metab. 2003, 88, 1217-1222. [CrossRef] [PubMed]

13. Ogland, B.; Forman, M.R.; Romundstad, P.R.; Nilsen, S.T.; Vatten, L.J. Blood pressure in early adolescence in the offspring of preeclamptic and normotensive pregnancies. J. Hypertens. 2009, 27, 2051-2054. [CrossRef] [PubMed]

14. Fraser, A.; Nelson, S.M.; Macdonald-Wallis, C.; Sattar, N.; Lawlor, D.A. Hypertensive Disorders of Pregnancy and Cardiometabolic Health in Adolescent Offspring. Hypertension 2013, 62, 614-620. [CrossRef] [PubMed]

15. Staley, J.R.; Bradley, J.; Silverwood, R.J.; Howe, L.D.; Tilling, K.M.; Lawlor, D.A.; Macdonald-Wallis, C. Associations of Blood Pressure in Pregnancy With Offspring Blood Pressure Trajectories During Childhood and Adolescence: Findings From a Prospective Study. J. Am. Hear. Assoc. 2015, 4, 4. [CrossRef]

16. Lazdam, M.; De La Horra, A.; Diesch, J.; Kenworthy, Y.; Davis, E.; Lewandowski, A.J.; Szmigielski, C.; Shore, A.C.; MacKillop, L.; Kharbanda, R.K.; et al. Unique Blood Pressure Characteristics in Mother and Offspring After Early Onset Preeclampsia. Hypertension 2012, 60, 1338-1345. [CrossRef]

17. Lim, W.-Y.; Lee, Y.-S.; Yap, F.K.-P.; Aris, I.M.; Lek, N.; Meaney, M.; Gluckman, P.D.; Godfrey, K.M.; Kwek, K.; Chong, Y.-S.; et al. Maternal Blood Pressure During Pregnancy and Early Childhood Blood Pressures in the Offspring. Medicine 2015, 94, e1981. [CrossRef]

18. Rostand, S.G.; Cliver, S.P.; Goldenberg, R.L. Racial disparities in the association of foetal growth retardation to childhood blood pressure. Nephrol. Dial. Transplant. 2005, 20, 1592-1597. [CrossRef]

19. Lu, J.; Zhang, S.; Li, W.; Leng, J.; Wang, L.; Liu, H.; Li, W.; Zhang, C.; Qi, L.; Tuomilehto, J.; et al. Maternal Gestational Diabetes Is Associated With Offspring's Hypertension. Am. J. Hypertens. 2019, 32, 335-342. [CrossRef]

20. Wright, C.S.; Rifas-Shiman, S.L.; Rich-Edwards, J.W.; Taveras, E.M.; Gillman, M.W.; Oken, E. Intrauterine Exposure to Gestational Diabetes, Child Adiposity, and Blood Pressure. Am. J. Hypertens. 2009, 22, 215-220. [CrossRef]

21. Perng, W.; Hockett, C.W.; Sauder, K.A.; Dabelea, D. In utero exposure to gestational diabetes mellitus and cardiovascular risk factors in youth: A longitudinal analysis in the EPOCH cohort. Pediatr. Obes. 2020, 15, e12611. [CrossRef] [PubMed]

22. Beukers, F.; Rotteveel, J.; Ganzevoort, W.; Van Weissenbruch, M.M.; Van Goudoever, J.B.; Van Wassenaer-Leemhuis, A.G. Blood pressure of 12-year-old children born after foetal growth restriction due to hypertensive disorders of pregnancy; relation to neonatal, life style, and family characteristics. Early Hum. Dev. 2019, 130, 33-37. [CrossRef] [PubMed]

23. Perng, W.; Ringham, B.M.; Smith, H.A.; Michelotti, G.; Kechris, K.M.; Dabelea, D. A prospective study of associations between in utero exposure to gestational diabetes mellitus and metabolomic profiles during late childhood and adolescence. Diabetologia 2020, 63, 296-312. [CrossRef] [PubMed] 
24. Lowe, W.L.; Scholtens, D.M.; Kuang, A.; Linder, B.; Lawrence, J.M.; Lebenthal, Y.; McCance, D.R.; Hamilton, J.K.; Nodzenski, M.; Talbot, O.; et al. Hyperglycemia and Adverse Pregnancy Outcome Follow-up Study (HAPO FUS): Maternal Gestational Diabetes Mellitus and Childhood Glucose Metabolism. Diabetes Care 2019, 42, 372-380. [CrossRef]

25. Jayet, P.-Y.; Rimoldi, S.F.; Stuber, T.; Salmoòn, C.S.; Hutter, D.; Rexhaj, E.; Thalmann, S.; Schwab, M.; Turini, P.; Sartori-Cucchia, C.; et al. Pulmonary and Systemic Vascular Dysfunction in Young Offspring of Mothers With Preeclampsia. Circulation 2010, 122, 488-494. [CrossRef]

26. Sarvari, S.I.; Rodríguez-López, M.; Nunez-Garcia, M.; Sitges, M.; Sepúlveda-Martínez, A.; Camara, O.; Butakoff, C.; Gratacós, E.; Bijnens, B.; Crispi, F. Persistence of Cardiac Remodeling in Preadolescents with Fetal Growth Restriction. Circ. Cardiovasc. Imaging 2017, 10, e005270. [CrossRef]

27. Yiallourou, S.R.; Wallace, E.M.; Whatley, C.; Odoi, A.; Hollis, S.; Weichard, A.J.; Muthusamy, J.S.; Varma, S.; Cameron, J.D.; Narayan, O.; et al. Sleep: A Window Into Autonomic Control in Children Born Preterm and Growth Restricted. Sleep 2017, 40. [CrossRef]

28. Patey, O.; Carvalho, J.S.; Thilaganathan, B. Perinatal changes in cardiac geometry and function in growth-restricted fetuses at term. Ultrasound Obstet. Gynecol. 2019, 53, 655-662. [CrossRef]

29. Cohen, E.; Whatley, C.; Wong, F.Y.; Wallace, E.M.; Mockler, J.C.; Odoi, A.; Hollis, S.; Horne, R.S.; Yiallourou, S.R. Effects of foetal growth restriction and preterm birth on cardiac morphology and function during infancy. Acta Paediatr. 2018, 107, 450-455. [CrossRef]

30. Lunddorf, L.L.H.; Brix, N.; Ernst, A.; Arendt, L.H.; Støvring, H.; Clemmensen, P.J.; Olsen, J.; Ramlau-Hansen, C.H. Hypertensive disorders in pregnancy and timing of pubertal development in daughters and sons. Hum. Reprod. 2020, 35, 2124-2133. [CrossRef]

31. Martinez, M.P.; Lin, J.; Chow, T.; Chung, J.; Wang, X.; Xiang, A.H. Maternal Gestational Diabetes and Type 2 Diabetes During Pregnancy and Risk of Childhood Asthma in Offspring. J. Pediatr. 2020, 219, 173-179.e1. [CrossRef] [PubMed]

32. Li, P.; Xiong, T.; Hu, Y. Hypertensive disorders of pregnancy and risk of asthma in offspring: Protocol for a systematic review and meta-analysis. BMJ Open 2020, 10, e035145. [CrossRef]

33. Berkelhamer, S.K.; Mestan, K.K.; Steinhorn, R.H. An update on the diagnosis and management of bronchopulmonary dysplasia (BPD)-associated pulmonary hypertension. Semin. Perinatol. 2018, 42, 432-443. [CrossRef] [PubMed]

34. Lagatta, J.M.; Hysinger, E.B.; Zaniletti, I.; Wymore, E.M.; Vyas-Read, S.; Yallapragada, S.; Nelin, L.D.; Truog, W.E.; Padula, M.A.; Porta, N.F.; et al. The Impact of Pulmonary Hypertension in Preterm Infants with Severe Bronchopulmonary Dysplasia through 1 Year. J. Pediatr. 2018, 203, 218-224.e3. [CrossRef] [PubMed]

35. Naumburg, E.; Söderström, L. Increased risk of pulmonary hypertension following premature birth. BMC Pediatr. 2019, 19, 1-7. [CrossRef]

36. Libby, G.; Murphy, D.J.; McEwan, N.F.; Greene, S.A.; Forsyth, J.S.; Chien, P.W.; Morris, A.D.; DARTS/MEMO Collaboration. Pre-eclampsia and the later development of type 2 diabetes in mothers and their children: An intergenerational study from the Walker cohort. Diabetologia 2007, 50, 523-530. [CrossRef]

37. Garcia-Vargas, L.; Addison, S.S.; Nistala, R.; Kurukulasuriya, D.; Sowers, J.R. Gestational Diabetes and the Offspring: Implications in the Development of the Cardiorenal Metabolic Syndrome in Offspring. Cardiorenal Med. 2012, 2, 134-142. [CrossRef]

38. Uemura, O.; Ishikura, K.; Kaneko, T.; Hirano, D.; Hamasaki, Y.; Ogura, M.; Mikami, N.; Gotoh, Y.; Sahashi, T.; Fujita, N.; et al. Perinatal factors contributing to chronic kidney disease in a cohort of Japanese children with very low birth weight. Pediatr. Nephrol. 2020,1-8. [CrossRef]

39. Hoogenboom, L.A.; Wolfs, T.G.A.M.; Hütten, M.C.; Peutz-Kootstra, C.J.; Schreuder, M.F. Prematurity, perinatal inflammatory stress, and the predisposition to develop chronic kidney disease beyond oligonephropathy. Pediatr. Nephrol. 2020, 1-9. [CrossRef]

40. Leybovitz-Haleluya, N.; Wainstock, T.; Landau, D.; Sheiner, E. Maternal gestational diabetes mellitus and the risk of subsequent pediatric cardiovascular diseases of the offspring: A population-based cohort study with up to 18 years of follow up. Acta Diabetol. 2018, 55, 1037-1042. [CrossRef]

41. Walter, E.; Tsumi, E.; Wainstock, T.; Spiegel, E.; Sheiner, E. Maternal gestational diabetes mellitus: Is it associated with long-term pediatric ophthalmic morbidity of the offspring? J. Matern. Neonatal Med. 2019, 32, 2529-2538. [CrossRef] [PubMed] 
42. Ornoy, A.; Ratzon, N.; Greenbaum, C.; Wolf, A.; Dulitzky, M. School-age Children Born to Diabetic Mothers and to Mothers with Gestational Diabetes Exhibit a High Rate of Inattention and Fine and Gross Motor Impairment. J. Pediatr. Endocrinol. Metab. 2001, 14, 681-690. [CrossRef] [PubMed]

43. He, X.-J.; Dai, R.-X.; Tian, C.-Q.; Hu, C.-L. Neurodevelopmental outcome at 1 year in offspring of women with gestational diabetes mellitus. Gynecol. Endocrinol. 2020, 21, 1-5. [CrossRef] [PubMed]

44. Noda, M.; Yoshida, S.; Mishina, H.; Matsubayashi, K.; Kawakami, K. Association between maternal hypertensive disorders of pregnancy and child neurodevelopment at 3 years of age: A retrospective cohort study. J. Dev. Orig. Health Dis. 2020, 1-8. [CrossRef] [PubMed]

45. Marcelle, E.T.; Oliva, M.T.; Hinshaw, S.P. Gestational Smoking and Hypertension as Predictors of Working Memory Functioning in Childhood Attention-Deficit/Hyperactivity Disorder. Front. Psychol. 2020, 11, 1950. [CrossRef] [PubMed]

46. Dachew, B.A.; Scott, J.G.; Betts, K.; Mamun, A.; Alati, R. Hypertensive disorders of pregnancy and the risk of offspring depression in childhood: Findings from the Avon Longitudinal Study of Parents and Children. Dev. Psychopathol. 2020, 32, 845-851. [CrossRef]

47. Dachew, B.A.; Scott, J.G.; Mamun, A.; Alati, R. Hypertensive disorders of pregnancy and emotional and behavioural problems in children: A longitudinal population-based study. Eur. Child Adolesc. Psychiatry 2020, 29, 1-10. [CrossRef]

48. Monteith, C.; Flood, K.; Pinnamaneni, R.; Levine, T.A.; Alderdice, F.A.; Unterscheider, J.; McAuliffe, F.M.; Dicker, P.; Tully, E.C.; Malone, F.D.; et al. An abnormal cerebroplacental ratio (CPR) is predictive of early childhood delayed neurodevelopment in the setting of fetal growth restriction. Am. J. Obstet. Gynecol. 2019, 221, 273.e1-273.e9. [CrossRef]

49. Delorme, P.; Kayem, G.; Lorthe, E.; Sentilhes, L.; Zeitlin, J.; Subtil, D.; Rozé, J.C.; Vayssière, C.; Durox, M.; Ancel, P.Y.; et al. Neurodevelopment at 2 years and umbilical artery Doppler in cases of very preterm birth after prenatal hypertensive disorder or suspected fetal growth restriction: EPIPAGE -2 prospective population-based cohort study. Ultrasound Obstet. Gynecol. 2020, 56, 557-565. [CrossRef]

50. Tomlinson, M.S.; Santos, H.P.; Stewart, J.; Joseph, R.; Leviton, A.; Onderdonk, A.B.; Kuban, K.C.K.; Heeren, T.; O'Shea, T.M.; Fry, R.C.; et al. Neurocognitive and social-communicative function of children born very preterm at 10 years of age: Associations with microorganisms recovered from the placenta parenchyma. J. Perinatol. 2020, 40, 306-315. [CrossRef]

51. Räikkönen, K.; Gissler, M.; Kajantie, E. Associations Between Maternal Antenatal Corticosteroid Treatment and Mental and Behavioral Disorders in Children. JAMA 2020, 323, 1924-1933. [CrossRef] [PubMed]

52. Hromadnikova, I.; Kotlabova, K.; Dvorakova, L.; Krofta, L.; Sirc, J. Postnatal Expression Profile of microRNAs Associated with Cardiovascular and Cerebrovascular Diseases in Children at the Age of 3 to 11 Years in Relation to Previous Occurrence of Pregnancy-Related Complications. Int. J. Mol. Sci. 2019, $20,654$. [CrossRef] [PubMed]

53. Hromadnikova, I.; Kotlabova, K.; Dvorakova, L.; Krofta, L.; Sirc, J. Substantially Altered Expression Profile of Diabetes/Cardiovascular/Cerebrovascular Disease Associated microRNAs in Children Descending from Pregnancy Complicated by Gestational Diabetes Mellitus-One of Several Possible Reasons for an Increased Cardiovascular Risk. Cells 2020, 9, 1557. [CrossRef]

54. Inzaghi, E.; Kistner, A.; Germani, D.; Deodati, A.; Vanpee, M.; Legnevall, L.; Berinder, K.; Cianfarani, S. A prospective case-control study on miRNA circulating levels in subjects born small for gestational age (SGA) evaluated from childhood into young adulthood. PLOS ONE 2020, 15, e228075. [CrossRef]

55. Chen, R.; Xin, G.; Zhang, X. Long non-coding RNA HCP5 serves as a ceRNA sponging miR-17-5p and $\mathrm{miR}-27 \mathrm{a} / \mathrm{b}$ to regulate the pathogenesis of childhood obesity via the MAPK signaling pathway. J. Pediatr. Endocrinol. Metab. 2019, 32, 1327-1339. [CrossRef]

56. Benite-Ribeiro, S.A.; Putt, D.A.; Soares-Filho, M.C.; Santos, J.M. The link between hypothalamic epigenetic modifications and long-term feeding control. Appetite 2016, 107, 445-453. [CrossRef]

57. Liao, J.; Huang, J.; Wang, S.; Xiang, M.; Wang, D.; Deng, H.; Yin, H.; Xu, F.; Hu, M. Effects of exercise and diet intervention on appetite-regulating hormones associated with miRNAs in obese children. Eat. Weight. Disord. 2020, 1-9. [CrossRef]

58. Marzano, F.; Faienza, M.F.; Caratozzolo, M.F.; Brunetti, G.; Chiara, M.; Horner, D.S.; Annese, A.; D’Erchia, A.M.; Consiglio, A.; Pesole, G.; et al. Pilot study on circulating miRNA signature in children with obesity born small for gestational age and appropriate for gestational age. Pediatr. Obes. 2018, 13, 803-811. [CrossRef] 
59. Khalyfa, A.; Kheirandish-Gozal, L.; Bhattacharjee, R.; Khalyfa, A.A.; Gozal, D. Circulating microRNAs as Potential Biomarkers of Endothelial Dysfunction in Obese Children. Chest 2016, 149, 786-800. [CrossRef]

60. International Association of Diabetes and Pregnancy Study Groups Consensus Panel; Metzger, B.E.; Gabbe, S.G.; Persson, B.; Buchanan, T.A.; Catalano, P.A.; Damm, P.; Dyer, A.R.; Leiva, A.D.; Hod, M.; et al. International association of diabetes and pregnancy study groups recommendations on the diagnosis and classification of hyperglycemia in pregnancy. Diabetes Care 2010, 33, 676-682. [CrossRef]

61. ACOG Practice Bulletin No. 33. Diagnosis and Management of Preeclampsia and Eclampsia. Obstet. Gynecol. 2002, 99, 159-167. [CrossRef]

62. Figueras, F.; Gratacos, E. Stage-based approach to the management of fetal growth restriction. Prenat. Diagn. 2014, 34, 655-659. [CrossRef] [PubMed]

63. Baschat, A.A. Neurodevelopment following fetal growth restriction and its relationship with antepartum parameters of placental dysfunction. Ultrasound Obstet. Gynecol. 2011, 37, 501-514. [CrossRef] [PubMed]

64. Nardozza, L.M.M.; Caetano, A.C.R.; Zamarian, A.C.P.; Mazzola, J.B.; Silva, C.P.; Marçal, V.M.G.; Lobo, T.F.; Peixoto, A.B.; Júnior, E.A. Fetal growth restriction: Current knowledge. Arch. Gynecol. Obstet. 2017, 295, 1061-1077. [CrossRef]

65. Goldenberg, R.L.; Culhane, J.F.; Iams, J.D.; Romero, R. Epidemiology and causes of preterm birth. Lancet 2008, 371, 75-84. [CrossRef]

66. Moutquin, J.M.; Milot Roy, V.; Irion, O. Preterm prevention: Effectivenss of current strategies. J. Soc. Obstet. Gynaecol. Can. 1996, 18, 571-588. [CrossRef]

67. Romero, R.; Espinoza, J.; Kusanovic, J.P.; Gotsch, F.; Hassan, S.; Erez, O.; Chaiworapongsa, T.; Mazor, M. The preterm parturition syndrome. BJOG 2006, 113, 17-42. [CrossRef]

68. National High Blood Pressure Education Program Working Group on High Blood Pressure in Children and Adolescents. The fourth report on the diagnosis, evaluation, and treatment of high blood pressure in children and adolescents. Pediatrics 2004, 114, 555-576. [CrossRef]

69. Livak, K.J.; Schmittgen, T.D. Analysis of relative gene expression data using real-time quantitative PCR and the 2(-Delta Delta C(T)) method. Methods 2001, 25, 402-408. [CrossRef]

70. Vandesompele, J.; De Preter, K.; Pattyn, F.; Poppe, B.; Van Roy, N.; De Paepe, A.; Speleman, F. Accurate normalization of real-time quantitative RT-PCR data by geometric averaging of multiple internal control genes. Genome Biol. 2002, 3, 0034. [CrossRef]

71. Shapiro, S.S.; Wilk, M.B. An analysis of variance test for normality (complete samples). Biometrika 1965, 52, 591-611. [CrossRef]

Publisher's Note: MDPI stays neutral with regard to jurisdictional claims in published maps and institutional affiliations.

(C) 2020 by the authors. Licensee MDPI, Basel, Switzerland. This article is an open access article distributed under the terms and conditions of the Creative Commons Attribution (CC BY) license (http://creativecommons.org/licenses/by/4.0/). 